\title{
Decompensative gravity anomalies reveal structure of the upper crust of Antarctica.
}

\author{
Mikhail K. Kaban $(1,2)$ and Carina Haeger $(1,3)$ \\ (1) GeoForschungsZentrum Potsdam, Potsdam, Germany (kaban@gfz-potsdam.de), (2) Schmidt Institute of Physics of the \\ Earth, Moscow, Russia, (3) Free University Berlin, Germany
}

Despite a big progress in the study of the Antarctic ice shield, still little is known about the structure of the upper crust including sedimentary basins, which are hidden under the ice. In this work, we infer density heterogeneity of the upper crust of Antarctica by computing decompensative anomalies of the gravity field. These anomalies are based on the isostatic anomalies, which are initially computed using the observed gravity field (satellite and terrestrial models), basement topography, ice thickness provided by the Bedmap2 project (Fretwell et al., 2013) and bathymetry of the surrounding ocean. In the isostatic model, we have also taken into account variations of the effective elastic thickness of the lithosphere and Moho depth from previous studies. Although the isostatic anomalies chiefly reflect the upper crust density heterogeneities, their impact is substantially reduced by isostatic compensation. To refine this effect from the deep sources, we applied a so-called decompensative correction (Kaban et al., 2017). Therefore, the computed decompensative gravity anomalies are most appropriate to study the upper crust density structure. The obtained decompensative anomalies well correspond to the known sedimentary basins, such as in the areas of the Filchner-Ronne Ice Shelf and Lambert Graben, however they suggest the existence of other large sedimentary deposits both in West and East Antarctica, which are not yet revealed due to a lack of seismic surveys. The extended positive anomaly in East Antarctica is likely related to the old and dense cratonic crust.

Fretwell, P., Pritchard, H. D., Vaughan, D. G., Bamber, J. L., Barrand, N. E., Bell, R., ... Zirizzotti, A. (2013). Bedmap2: Improved ice bed, surface and thickness datasets for Antarctica. Cryosphere, 7(1), 375-393. https://doi.org/10.5194/tc-7-375-2013

Kaban, M. K., El Khrepy, S., \& Al-Arifi, N. (2017). Importance of the Decompensative Correction of the Gravity Field for Study of the Upper Crust: Application to the Arabian Plate and Surroundings. Pure and Applied Geophysics, 174(1), 349-358. 